\title{
Identification of Epitopes Recognized by Monoclonal Antibodies SM1 and SM2 Which React with All Pili of Neisseria gonorrhoeae but Which Differentiate between Two Structural Classes of Pili Expressed by Neisseria meningitidis and the Distribution of Their Encoding Sequences in the Genomes of Neisseria spp.
}

\author{
By MUMTAZ VIRJI, $\dagger^{1}$ JOHN E. HECKELS, $^{1}$ WENDY J. POTTS,${ }^{2} \ddagger$ \\ C. A. HART ${ }^{3}$ AND J. R. SAUNDERS ${ }^{3 *}$ \\ ${ }^{1}$ Department of Microbiology, Southamptom University Medical School, Southampton General \\ Hospital, Tremona Road, Southampton SO9 4 XY, UK \\ ${ }^{2,3}$ Departments of Genetics and Microbiology ${ }^{2}$ and Medical Microbiology ${ }^{3}$, \\ University of Liverpool, PO Box 147, Liverpool L69 3BX, UK
}

(Received 24 April 1989; revised 10 August 1989; accepted 15 August 1989)

The pili expressed by all isolates of Neisseria gonorrhoeae react with two monoclonal antibodies, SM1 and SM2. In contrast, although many isolates of Neisseria meningitidis also express pili (class I) which react with antibodies SM1 and SM2, a proportion express pili (class II) which fail to react. In order to define the epitopes recognized by these antibodies, a series of overlapping peptides corresponding to the amino acid sequence of conserved regions of gonococcal pili have been synthesized. The minimum epitope recognized by antibody SM1 was found to comprise a linear peptide EYYLN, corresponding to residues 49-53 of mature pilin. In contrast, antibody SM2 reacted with a number of peptides from around the cysteine residue (Cys 1 ) at position 120, suggesting that an extended region may contribute to a conformational epitope recognized by this antibody in the native protein. The identification of the two epitopes defines structural differences between the classes of pili expessed by meningococci. In order to determine the distribution of pilin gene sequences in Neisseria we used as hybridization probes an oligonucleotide (PS1) with the sequence 5'-GAGTATTACCTGAATCA-3' which spans the coding region for the SM1 epitope, and a fragment of the $3^{\prime}$ end of the gonococcal pilE gene which contains conserved sequences flanking the two Cys codons and encodes the SM2 epitope. All strains of $N$. gonorrhoeae and $N$. meningitidis tested, regardless of piliation phenotype, harboured DNA sequences homologous to those encoding the carboxy-terminus of meningococcal class I pilin. Furthermore, all gonococci and all meningocococci producing class I pili hybridized with oligonucleotide probe PS1. Non-reverting non-piliated derivatives of previously class I pilus-producing strains showed reduced hybridization signals with this probe, but nevertheless retained sequences homologous to the coding sequence for the SM1 epitope. However, meningococci producing class II pili could be divided into two groups on the basis of their reaction with the PSI probe: half the strains tested failed to react, which is consistent with our previous analysis of silent class I pilin sequences; the remainder reacted (relatively weakly) with the probe, suggesting that the silent pil sequences in these strains extend further towards the $5^{\prime}$ end of the pilin gene than in strains studied previously. Some strains of Neisseria lactamica reacted weakly with both types of probe but failed to produce SM1-reactive pili. In contrast,

\footnotetext{
† Present address: Department of Pediatrics, University of Oxford, John Radcliffe Hospital, Headington, Oxford OX3 9DU, UK.

‡ Present address: ICI Diagnostics, Gadbrook Park, Rudheath, Northwich, Cheshire CW9 7RA, UK.
}

Abbreviation: mAb, monoclonal antibody. 
isolates of Neisseria flava, Neisseria pharyngis, Nesseria sicca and a series of unrelated bacteria failed to react with both SMI antibody and the DNA probes. This confirms that possession of 'gonococcal' pilin sequences is limited to the pathogenic neisseriae.

\section{INTRODUCTION}

Pili (fimbriae) are filamentous appendages present on the surface of pathogenic neisseriae which are thought to play an essential role in virulence (Swanson, 1973; Ward et al., 1974). Fresh gonococcal isolates are invariably piliated, and loss of pilus expression on laboratory subculture has been correlated with loss of the ability to cause infection in human volunteers (Kellog et al., 1963; Swanson et al., 1971). Many studies have subsequently reported that the association between pilus expression and virulence results from the ability of pili to facilitate adhesion of gonococci to the mucosal surfaces of the genital tract, the essential first stage in pathogenesis of gonococcal infection (reviewed by Heckels, 1989). Although the association of piliation with meningococcal disease is less well established, fresh meningococcal isolates from both blood and cerebrospinal fluid are invariably piliated, and pili facilitate adhesion of meningococci to nasopharyngeal cells in vitro, suggesting that they play an important role in colonization of the mucosal surfaces of the nasopharynx (Stephens \& McGee, 1981; Trust et al., 1983).

Gonococcal pili exhibit considerable structural and antigenic diversity not only between strains but also within a strain so that antigenic shift in pilus expression during the course of an infection allows gonococci to evade the consequences of the host immune response (Zak et al., 1984). Analysis of the predicted amino acid sequence of cloned genes has revealed that pili are assembled from a repeating array of a pilin polypeptide subunit which varies in apparent $M_{\mathrm{r}}$ in the range 17000-22000 between antigenic variants of a strain (Hagblom et al., 1985; Nicolson et $a l ., 1987 b$ ). Such pilins contain distinct conserved (C) and variable (SV and HV) regions but the variable determinants are immunodominant so that the variant pili show little or no antigenic cross-reactivity (Virji et al., 1982). Despite this antigenic heterogeneity, two monoclonal antibodies (mAbs), SM1 and SM2, have been produced that react with pili on all gonococcal isolates so far tested (Virji \& Heckels, 1983).

Use of $\mathrm{mAbs}$ SM1 and SM2 has revealed that meningococcal pili show even greater antigenic diversity than those of gonococci. Many strains produce pilins which closely resemble gonococcal pilins in apparent $M_{\mathrm{r}}$ and reactivity with mAbs SM1 and SM2 (Diaz et al., 1984), in possessing strong homology at the amino acid sequence level (Potts \& Saunders, 1988) and in undergoing antigenic variation during infection (Tinsley \& Heckels, 1986). Other strains produce pilins that fail to react with either $\mathrm{mAb}$ but react with polyclonal antisera raised against gonococcal pili to reveal pilins with apparent $M_{\mathrm{r}}$ in the range 13000-16000 (Diaz et al., 1984; Perry et al., 1987a). These two types of meningococcal pili have been given a variety of designations by different authors, namely group 1 and group 2 (Diaz et al., 1984), SM1-reactive and SM2-nonreactive (Achtman et al., 1988) and class I and class II (Perry et al., 1988); the last has subsequently been adopted as the recognized nomenclature (Hitchcock, 1989).

Gonococcal and meningococcal pili are characteristically subject, both in vivo and in vitro, to phase and antigenic variation caused by recombinational events that involve the insertion of alternative silent partial pilin (pilS) sequences into a pilin expression (pilE) locus (Haas \& Meyer, 1986; Hagblom et al., 1985; Potts \& Saunders, 1988; Segal et al., 1986; Seiffert et al., 1988). The presence of DNA sequences homologous to the entire structural gene for gonococcal pilin (pilE) appears to be limited to the pathogenic members of the genus Neisseria (Aho et al., 1987). Despite failing to encode class I pili, the chromosomes of two independently isolated class II pilus-producing meningococci have been shown to contain silent pil sequences that are homologous to regions of the central semivariable (SV) and carboxy-terminal hypervariable (HV) coding portions of the gonococcal pilE pilin structural gene (Aho \& Cannon, 1988; Perry et al., 1988).

mAbs SM1 and SM2 have been used in several studies of meningococcal piliation to detect expression, to differentiate between the two classes of pili and to examine pilus antigenic variation (Diaz et al., 1984; Olafson et al., 1985; Achtman et al., 1988; Potts \& Saunders, 1988). 
Here we describe the synthesis of peptides corresponding to conserved regions of the gonococcal pilin molecule to locate the epitopes recognized by these mAbs which define the two classes of meningococcal pili. This paper also reports a study of the distribution of the coding sequences for the SM1 epitope and the carboxy-terminus of class I pilin among pathogenic and commensal Neisseria species.

\section{METHODS}

Bacterial strains and plasmids. N. gonorrhoeae $\mathrm{P} 9$ (Lambden et al., 1981) and N. meningitidis strains C311 (a class I pilus producer) and C114 (a class II pilus producer) (Perry et al., 1987a) have been described previously. Escherichia coli strain DHI (Hanahan, 1983) was used for the propagation of plasmid recombinants containing pilE gene probes. The remaining bacteria were all clinical isolates from Alder Hey Children's Hospital, Liverpool, that had been subcultured not more than twice prior to screening. All Neisseria strains were cultured on heated blood or clear typing agar (CTA) as described previously (Perry et al., 1987a). The remaining bacteria were grown aerobically [with the exception of Bacteroides spp., which were grown anaerobically in Gaspak jars (Becton Dickinson)] at $37^{\circ} \mathrm{C}$ on fresh horse blood agar plates (Oxoid blood agar base, $12 \mathrm{~g}$; horse blood, $70 \mathrm{ml}$; distilled water to $1000 \mathrm{ml}$ ).

Reagents and enzymes. Reagents, with the exception of Tris (Boehringer Mannheim) and bovine serum albumin (Sigma), were supplied by BDH. Restriction endonucleases, polymerases, ribonuclease $\mathrm{A}$ and proteinase $\mathrm{K}$ were supplied by Boehringer Mannheim.

$m A b s$ and immunological blotting. The production and properties of $\mathrm{mAbs} S \mathrm{SM} 1$ and SM2 have been described in detail previously (Virji et al., 1983; Virji \& Heckels, 1983). Procedures for immunological dot-blotting and Western blotting were as described previously (Nicolson et al., 1987a).

Synthesis of peptides and detection of immunological reactivity. Solid-phase peptide synthesis was carried out using a commercially available kit (Cambridge Research Biochemicals) in which peptides are synthesized on to polyethylene rods (Geyson et al., 1987). Peptides were synthesized as described previously (Virji \& Heckels, 1989) with pentafluorophenyl active esters of fluorenylmethoxycarbonyl-L-amino acids with t-butyl side-chainprotecting groups (Milligen), except in the case of serine and threonine, for which the oxybenzotriazine active ester was used. After synthesis, the terminal amino group was acetylated by reaction with acetic anhydride. Each synthesis was done in duplicate, and control peptides reacting with a mAb supplied by the manufacturer were included to check the coupling during each synthesis.

The immunological reactivities of the synthesized peptides on the rods were tested by ELISA as described previously (Virji \& Heckels, 1989). The rods were incubated with mAbs diluted 1:1000 in PBS containing 1\% $(\mathrm{w} / \mathrm{v}) \mathrm{BSA}, 1 \%(\mathrm{w} / \mathrm{v})$ ovalbumin and $0.1 \%(\mathrm{v} / \mathrm{v})$ Tween 20 . After washing and reaction with goat anti-mouse IgG conjugated to horseradish peroxidase (Zymed), colour was developed using 2,2'-azino-bis(3-ethylbenzthiazoline-6sulphonate) as substrate (Sigma). The solid-phase peptides were re-used after dissociation of bound antibody by sonication of the rods in $1 \%$ SDS, $0.1 \% 2$-mercaptoethanol in $0.1 \mathrm{M}$-phosphate buffer at $60^{\circ} \mathrm{C}$ for $30 \mathrm{~min}$. Immunological reactivity was always observed with duplicate peptides and in assays repeated on at least two occasions.

Preparation of DNA. Meningococcal genomic DNA was extracted from the bacteria obtained from three CTA plates spread to produce confluent growth, using a modification of the method of Kristiansen $e$ al. (1984). Cells were resuspended in $2 \mathrm{ml} 50 \mu \mathrm{m}-\mathrm{Tris} / \mathrm{HCl}(\mathrm{pH} 8.0), 25 \%$ (w/v) sucrose and then pelleted by centrifugation at $12000 \mathrm{~g}$ for $2 \mathrm{~min}$. The supernatant was discarded and $150 \mu \mathrm{l}$ of a solution containing $50 \mu \mathrm{m}-\mathrm{Tris} / \mathrm{HCl}, 25 \%(\mathrm{w} / \mathrm{v})$ sucrose, $5 \mathrm{mg}$ lysozyme $\mathrm{ml}^{-1}$ was added to the pellet. The mixture was vortexed briefly and incubated at $4{ }^{\circ} \mathrm{C}$ for $5 \mathrm{~min}$, followed by addition of $60 \mu \mathrm{l}$ ice-cold $0.25 \mathrm{M}$-EDTA, vortexing, and incubation for a further $5 \mathrm{~min}$ at $4{ }^{\circ} \mathrm{C}$. Then $300 \mu \mathrm{l}$ lysis solution $(50 \mathrm{~mm}$-Tris/HCl, $10 \mathrm{~mm}$-EDTA, $2 \%$, v/v, Triton X-100) and $100 \mu \mathrm{l}$ of a solution of proteinase $\mathrm{K}\left(5 \mathrm{mg} \mathrm{ml}^{-1}\right)$ was added and, following vortexing, the mixture was incubated at $4{ }^{\circ} \mathrm{C}$ for $60 \mathrm{~min}$. The resulting cell lysates were extracted three times with an equal volume of phenol/chloroform $(100 \mathrm{~g} \mathrm{phenol,} 0 \cdot 2 \mathrm{~g}$ hydroxyquinoline, $100 \mathrm{ml}$ chloroform, equilibrated with $0.1 \mathrm{M}-\mathrm{Tris} / \mathrm{HCl} \mathrm{pH} 8.0$ ) and once with chloroform. Ethidium bromide was added to $0.2 \mathrm{mg} \mathrm{ml}^{-1}$ and $\mathrm{CsCl}$ added to give a refractive index of 1.392 . The DNA was then banded by equilibrium density-gradient centrifugation at $180000 \mathrm{~g}$ for $18 \mathrm{~h}$ in an LKB Ultrospin 55 ultracentrifuge. DNA bands were extracted from the centrifuge tubes with $19 \mathrm{G}$ needles and syringes, and ethidium bromide removed by extraction with $\mathrm{NaCl}$ /water-saturated 2-propanol. The DNA solution was then dialysed against two changes of 1 litre of TE buffer $\left(0.01 \mathrm{M}\right.$-Tris/HCl, $0.001 \mathrm{M}$-EDTA, pH 8.0) over $6 \mathrm{~h}$ at $4{ }^{\circ} \mathrm{C}$. Finally the solution was phenol-extracted, ethanol-precipitated and resuspended in sterile double-distilled water.

Smaller amounts of DNA for dot blotting were isolated by a modification of the method of O'Reilly et al. (1986) from the growth of bacteria on the surface of one CTA or blood agar plate, depending on the organism. Cells were harvested in $2 \mathrm{ml}$ TES buffer $(100 \mathrm{mM}-\mathrm{NaCl}, 1 \mathrm{~mm}$-EDTA, $20 \mathrm{~mm}-\mathrm{Tris} / \mathrm{HCl}, \mathrm{pH} 8.0)$ and pelleted in a microcentrifuge at $12000 \mathrm{~g}$ for $2 \mathrm{~min}$. Then $1 \mathrm{ml}$ lysis mixture $(10 \mathrm{~mm}$-Tris/HCl, $10 \mathrm{~mm}-\mathrm{EDTA}, 100 \mathrm{~mm}-\mathrm{NaCl}$, 
$2 \%$, w.v SDS, $39 \mathrm{~mm}$-dithiothreitol, $50 \mu \mathrm{g}$ proteinase $\mathrm{K} \mathrm{ml}^{-1}$, pH 8.0; Gill et al., 1985) was added and, after vortexing, the mixture was incubated at $37^{\circ} \mathrm{C}$ for $30 \mathrm{~min}$. The lysate was extracted twice with phenol/ $\mathrm{CHCl}_{3}$ and used immediately for dot-blot hybridization. Alternatively, if the DNA was to be digested with restriction endonuclease, it was extracted once more with phenol/ $\mathrm{CHCl}_{3}$, ethanol-precipitated and resuspended in $150 \mu \mathrm{IE}$ buffer. Ribonuclease $\mathrm{A}\left(10 \mu \mathrm{l}\right.$ of a $10 \mathrm{mg} \mathrm{ml}^{-1}$ solution) was added and the mixture incubated at $37^{\circ} \mathrm{C}$ for $1 \mathrm{~h}$. The DNA was then ethanol-precipitated and finally resuspended in double-distilled water.

Plasmid DNA was extracted as described previously (Nicolson et al., 1987a).

DNA/DNA hybridization. The synthetic oligonucleotide PS1 (alias SM1) (5'-GAGTATTACCTGAATCA-3') (Potts \& Saunders, 1988) was produced using a Biosearch 3810 automatic DNA synthesizer employing phosphoramidite chemistry. Following purification by reverse-phase FPLC the probe was 5 -end labelled using phage T4 polynucleotide kinase (Boehringer) and [ $\gamma-{ }^{32}$ P]ATP (Amersham) by the procedure recommended by the manufacturers. The $0.42 \mathrm{~kb} \mathrm{BglI-ClaI}$ fragment of recombinant pLV830, which harbours sequences encoding the carboxy-terminal portion of the gene corresponding to $\mathrm{CNBr} 3$ fragment (Schoolnik et al., 1984) of pilin from N. meningitidis C311 (Potts \& Saunders, 1988), was used as a general probe for gonococcal and class I meningococcal pilin sequences. This restriction fragment was purified from agarose gels and labelled with $\left[\alpha^{-32} \mathrm{P}\right] \mathrm{CTP}$ (Amersham) using the random hexanucleotide priming reaction of Feinberg \& Vogelstein (1983) as described previously (Nicolson et al., 1987a). Hybridizations were carried out essentially as described previously (Sullivan \& Saunders, 1989) at $68^{\circ} \mathrm{C}$ with subsequent washing at room temperature for low-stringency and at $68^{\circ} \mathrm{C}$ for highstringency conditions. Dot-blotting was performed by applying approximately $10 \mu \mathrm{g}$ genomic DNA to nitrocellulose filters (BA85, Schleicher and Schuell) that had been presoaked in $6 \times \mathrm{SSC}(1 \times \mathrm{SSC}$ is $0 \cdot 15 \mathrm{M}-\mathrm{NaCl}$, $0.015 \mathrm{M}$-trisodium citrate, $\mathrm{pH} 7.0$ ) and fixed in a Schleicher and Schuell Minifold I apparatus. Filters were removed and placed sequentially for two separate 5 min periods each time on three sheets of Whatman $3 \mathrm{MM}$ paper soaked in (a) $0.5 \mathrm{M}-\mathrm{NaOH}$, then $(b) 1 \mathrm{M}$ - Tris/ $\mathrm{HCl}(\mathrm{pH} 8.0)$ and finally $(c)$ neutralizing solution $(1.0 \mathrm{M}-$ Tris $/ \mathrm{HCl} \mathrm{pH} 8.0,1.5 \mathrm{M}-\mathrm{NaCl}$ ). After drying in air, filters were baked in vacuo on a single sheet of $3 \mathrm{MM}$ paper at $80^{\circ} \mathrm{C}$ for $2 \mathrm{~h}$. Filters were then incubated at $68^{\circ} \mathrm{C}$ for $16 \mathrm{~h}$ in prehybridization buffer containing $6 \times \mathrm{SSC}, 10 \times$ Denhardt's solution ( $0.2 \%$ Ficoll; $0.2 \%$ polyvinylpyrrolidone; $0.2 \%$ bovine serum albumin) and denatured, sonicated calf thymus DNA $\left(50 \mu \mathrm{g} \mathrm{ml} \mathrm{ml}^{-1}\right)$. Hybridizations with oligonucleotide probes were done in prehybridization buffer containing $0.2 \mathrm{ng}$ of the oligonucleotide $\mathrm{ml}^{-1}$, for $2 \mathrm{~h}$. All hybridizations with DNA fragments as probes were carried out as described previously (Nicolson et al., 1987a). Hybridizations were carried out three times on each sample, with three separate DNA preparations in each case.

Electron microscopy. Bacteria were scraped from agar plates, resuspended to a concentration of approximately $10^{8} \mathrm{c}$.f.u. $\mathrm{ml}^{-1}$ in nutrient broth containing $2 \%(\mathrm{v} / \mathrm{v})$ horse serum and incubated at $37^{\circ} \mathrm{C}$ for $1 \mathrm{~h}$. The bacteria were then placed on carbon-Formvar-coated 200 mesh copper grids, stained with phosphotungstic acid $(2 \%, v / v)$ and examined using a Philips 301 electron microscope.

\section{RESULTS}

\section{Localization of epitope recognized by $M A b S M 1$}

Previous studies with synthetic peptides corresponding to the conserved region of the gonococcal pilin molecule revealed that $\mathrm{mAb}$ SMl reacted with a peptide corresponding to residues 48-60 (Heckels \& Virji, 1986). In addition, comparison of the predicted amino acid sequence of cloned gonococcal pilin genes showed significant variation between residues 54-60, suggesting that residues 48-53 must be sufficient for antibody binding (Nicolson et al., 1987b). With one exception, the amino acid sequences of all class I meningococcal pilins so far examined are identical in this region (Hermodsen et al., 1978; Potts \& Saunders, 1988). Pilin from $N$. meningitidis strain SP3428 reacts with mAb SM1 but contains valine at residue 48 (Olafson et al., $1985)$ rather than the more typical threonine (Potts \& Saunders, 1988). This indicates that the SM1 epitope should be no larger than the pentapeptide EYYLN. Synthetic decapeptides spanning the region 43-62 were therefore synthesized, with adjacent peptides overlapping by five residues. mAb SM1 reacted strongly with a single peptide corresponding to residues $48-57$ (Fig. 1a). A series of hexapeptides spanning this region were synthesized, with adjacent peptides differing by a single amino acid. Two peptides, TEYYLN (48-53) and EYYLNH (4954), reacted (Fig. 1b), as did the additional hexapeptide VEYYLN (Fig. 1c), corresponding to the equivalent residues 48-53 in pilin of $N$. meningitidis SP3428 (Olafson et al., 1985). Since the data suggested that the minimum epitope recognized by MAb SM1 is the sequence EYYLN (4953), this peptide was synthesized and also found to react (Fig. 1c). 


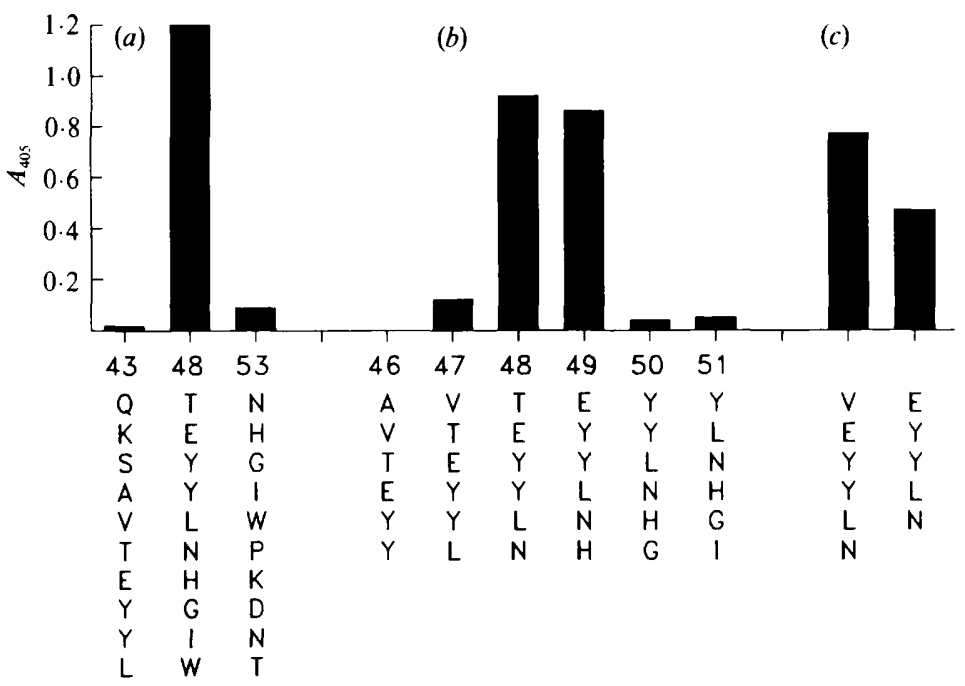

Fig. 1. Reaction of mAb SM1 with solid-phase synthetic peptides spanning the region of $43-62$ of the gonococcal pilin molecule: (a) decapeptides synthesized with a five amino acid overlap; $(b)$ adjacent hexapeptides synthesized with a single amino acid difference; $(c)$ variant peptide $48-53$ from meningococcal strain SP3428 (Olafson et al., 1985) and minimum reacting pentapeptide 49-53. For (a) and $(b)$ the residue number denotes the position within the pilin molecule of the first amino acid in each peptide.

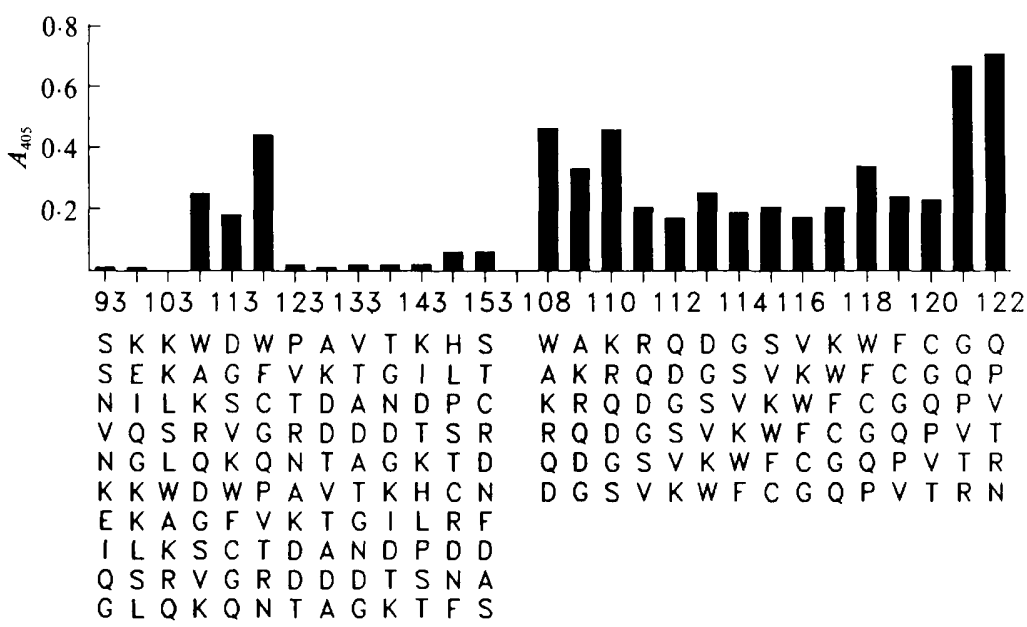

Fig. 2. Reaction of $\mathrm{mAbSM} 2$ with solid-phase synthetic peptides spanning the $\mathrm{CNBr} 3$ fragment of the gonococcal pilin molecule deduced from the nucleotide sequence of plasmid recombinant pLV260. (a) Decapeptides synthesized with a five amino acid overlap; $(b)$ adjacent hexapeptides synthesized with a single amino acid difference. The residue number denotes the position within the pilin molecule of the first amino acid in each peptide.

\section{Reaction of $m A b S M 2$ with synthetic peptides}

Previous studies with peptides derived from cyanogen bromide cleavage of pilin revealed that mAb SM2 reacted with fragment $\mathrm{CNBr} 3$, comprising the carboxy-terminal portion of the molecule (Virji \& Heckels, 1985). Using the deduced amino acid sequence of the cloned pilin gene on plasmid pLV260, derived from $N$. gonorrhoeae P9-2 (Nicolson et al., 1987a,b), a series of decapeptides were synthesized corresponding to fragment $\mathrm{CNBr} 3$ with adjacent peptides overlapping by five residues. Antibody SM2 reacted with the three adjacent peptides covering the sequence 108-127 (Fig. 2). Strongest reactivity was with the peptide WFCGQPVTRN, 


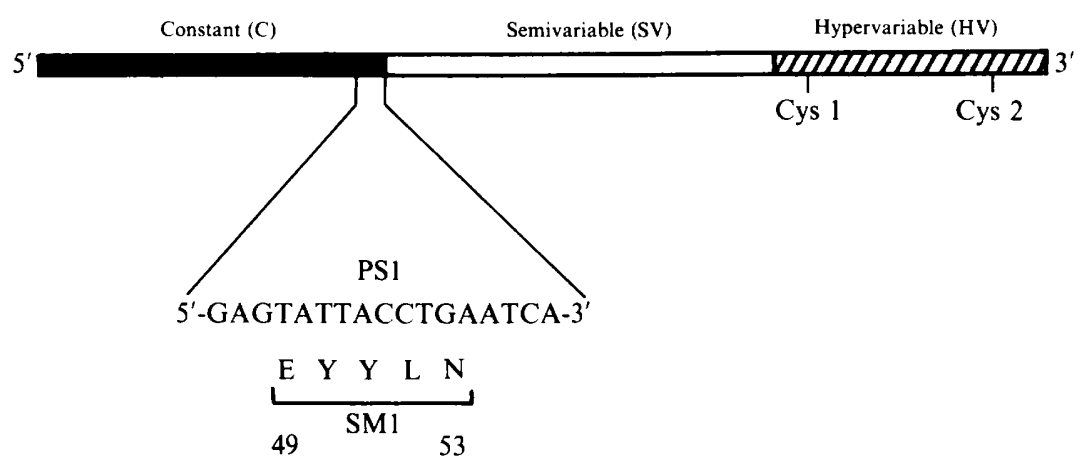

Fig. 3. Arrangement of the coding sequence for the mature gonococcal and meningococcal class I pilin molecule. The $5^{\prime}$ end represents the codon for phenylalanine at the amino-terminus of mature pilin. Promoter sequences and the coding region for the prepilin leader sequence are not shown. SM1 and PS1 represent the extent of the epitope and oligonucleotide probe, respectively.

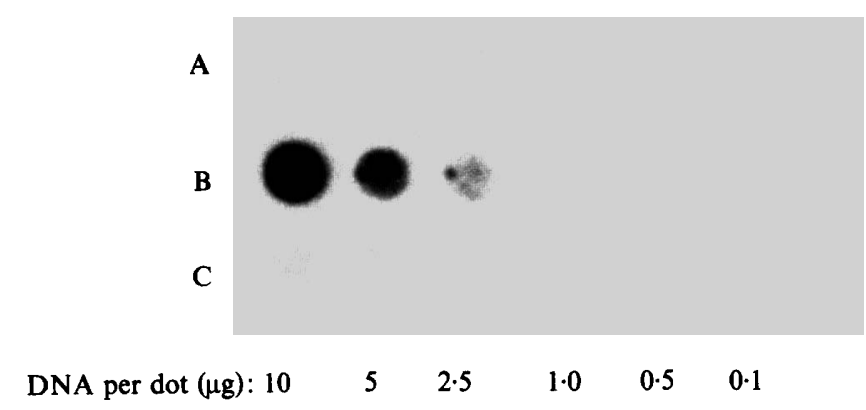

Fig. 4. DNA dot-blot hybridization of meningococcal DNA with oligonucleotide probe PS1. Columns

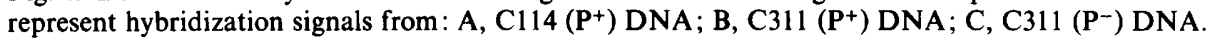

corresponding to residues 118-127. A series of hexapeptides spanning the region 108-127, with adjacent peptides differing by one amino acid, were synthesized. Antibody SM2 reacted to a variable extent with each of the hexapeptides, greatest reactivity being seen with the peptide $122-127$.

\section{Analysis of genomic sequences that encode the SMI-reactive epitope}

The 17-mer synthetic oligonucleotide PS1, which consists of the codon for pilin residue 49 through to the first two (conserved) nucleotides of the codon for residue 54 (Potts \& Saunders, 1988), was used as the hybridization probe for the coding region of the SMl epitope (Fig. 3). This 17-mer sequence is conserved in all expressed pilin ( pilE) genes in gonococci and class I pilusproducing meningococci for which DNA sequence data are available. The specificity of the PS1 oligonucleotide probe was tested by hybridization to genomic DNA extracted from SM1reactive and nonreactive meningococcal strains. No background hybridization was observed with DNA from strain C114 (Fig. 4, A), which expresses class II pili and possesses truncated silent class I pilin sequences that do not include the coding sequence for the SM1-reactive epitope (Perry et al., 1987a, 1988). Meningococcal strain C311, which expressed class I pili, showed strong hybridization with the oligonucleotide PS1, while a non-piliated variant derived from it gave a much weaker signal (Fig. 4, B, C). Since strain C311 exhibits distinct chromosomal rearrangements associated with pilus phase variation (Perry et al., 1987a), this presumably reflects the loss of one or more tracts of the genome that harbour PS1-homologous sequences. 

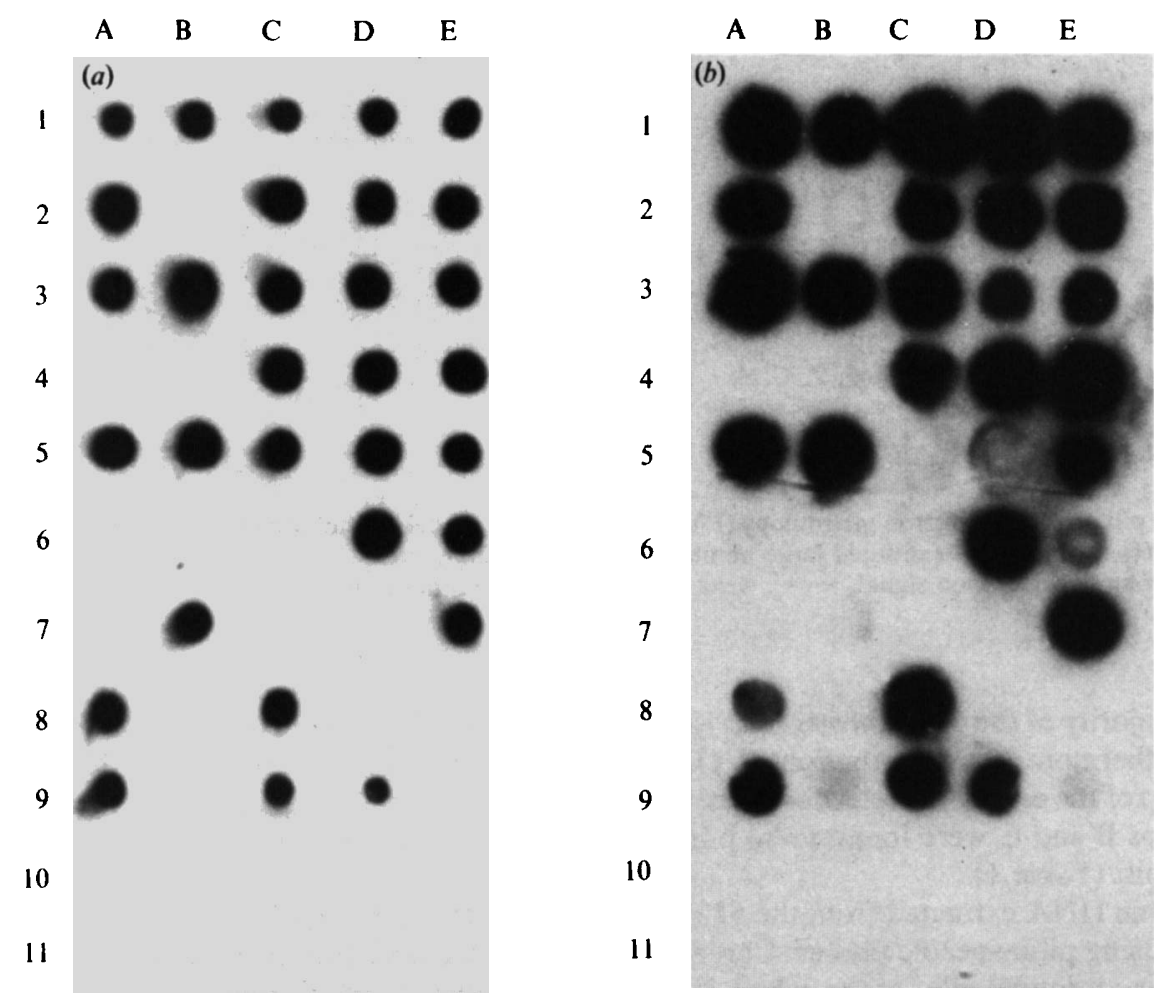

Fig. 5. Analysis of Neisseria isolates by immunological and DNA dot-blotting. Panels (a) and $(b)$ represent autoradiographs of immunological dot-blotting with antibody SMI and DNA dot-blot hybridization with oligonucleotide PS1 respectively. Each individual organism is arranged identically in each blot. Horizontal rows: $1-5, N$. meningitidis strains of serogroup $B ; 6-7, N$. meningitidis strains of serogroup $\mathrm{C} ; 8, N$. meningitidis strains of serogroups W135, X, Z, A;,$N$. gonorrhoeae strains; $10, N$. lactamica strains; 11, commensal Neisseria species (N. pharyngis, N. flava, N. sicca). Position $11 \mathrm{E}$ represents $E$. coli $\mathrm{DH} 1$. Vertical rows represent different isolates, sometimes from different sites in the same patient, of each serogroup.

\section{Distribution of the SMI epitope and DNA sequences homologous to class I meningococcal pilin genes among pathogenic and commensal Neisseria spp.}

A panel of 52 clinical isolates, including pathogenic and commensal Neisseria species, was analysed for the presence of pili, reaction with monoclonal antibody SM1, and presence of pilinspecific gene sequences (Fig. 5). Table 1 summarizes the responses of isolates of $N$. meningitidis to these tests. Several groups of meningococci were obtained from different locations in the same patient but did not necessarily show identical characteristics with respect to pilus expression, pilin production and hybridization to pilin probes. This suggests that these strains may be isogenic variants derived from a single parental isolate or, less probably, that patients may harbour a number of different meningococcal strains. This finding is consistent with previous observations showing that antigenic variation of surface structures takes place during the course of meningococcal infection (Tinsley \& Heckels, 1986). Meningococcal isolates either elaborated numerous individual pili or expressed pili that were aggregated in large bundles (data not shown), as has been observed by Greenblatt et al. (1988). Some meningococcal strains exhibited pili that were detached from the cell surface. Those isolates reacting with SM1 were considered to express class I pili. Piliated menincococci that failed to react with SM1 were presumed to produce class II pili. However, it was not possible in this limited study to determine any correlation between morphological differences and immunological reaction of meningococcal pili. 
Table 1. Piliation phenotypes of $N$. meningitidis isolates

\begin{tabular}{|c|c|c|c|c|}
\hline $\begin{array}{l}\text { No. of } \\
\text { isolates }\end{array}$ & Serogroup/serotype & $\begin{array}{l}\text { Pili visible } \\
\text { under } \mathrm{EM}^{*}\end{array}$ & $\begin{array}{l}\text { Reaction } \\
\text { with SM1 }\end{array}$ & $\begin{array}{l}\text { Hybridization } \\
\text { with PS1 }+\end{array}$ \\
\hline 16 & $\begin{array}{l}\text { B. } 15, \text { B.NT, B. } 16 \\
\text { NT. } 12\end{array}$ & $\mathrm{P}^{+}$ & + & + \\
\hline 8 & $\begin{array}{l}\text { B. } 15, \text { B.NT, B. } 16 \\
\text { C.NT, X }\end{array}$ & $\mathbf{P}^{-}$ & + & + \\
\hline 4 & $\begin{array}{l}\text { B. } 15 / 16, \text { NT. } 15 / 16 \\
\text { C.NT, C. } 2 \text { B }\end{array}$ & $\mathbf{P}^{+d}$ & + & $+1-$ \\
\hline 5 & C. $2 \mathrm{~A}, \mathrm{~W} 145, \mathrm{Z}, \mathrm{C} .2 \mathrm{~B}$ & $\mathbf{P}^{+}$ & - & $+1-$ \\
\hline 1 & B. 15 & $\mathbf{P}-$ & - & $+1-$ \\
\hline 5 & B.NT, C.2A, C.2B & $\mathbf{P}^{+}$ & - & - \\
\hline 1 & A & $\mathbf{P}^{-}$ & - & - \\
\hline
\end{tabular}

The majority of the $40 \mathrm{~N}$. meningitidis isolates analysed in this study elaborated SM1-reactive pili. Furthermore, the distribution of class I pili was apparently unrelated to the capsular serogroup of the organism tested, or to the source of the isolate. Meningococci belonging to both serogroups $\mathrm{B}$ and $\mathrm{C}$ were found to be piliated, some isolates possessing class I pili and others class II pili (Table 1).

Genomic DNA extracted from the 52 isolates was subjected to DNA dot-blot hybridization analysis using pilin-specific probes. Chromosomal DNA from all gonococci tested reacted with the carboxy-terminal pilin probe, which includes invariant domains around the two Cys codons of the gonococcal pilE gene (Hagblom et al., 1985; Perry et al., 1987 b), and also the codons for the SM2 epitope (residues 118-127).

All meningococcal isolates that reacted with SM1, and all gonococcal strains, harboured genomic sequences that hybridized to the synthetic oligonucleotide probe PS1 (Fig. 5, Table 1) even though examination of these strains by electron microscopy failed to reveal intact pili in some isolates. However, such non-piliated isolates showed hybridization signals with the same intensity as those of piliated isolates (Fig. 5) and contained SM1-reactive pilin when examined by Western blotting (data not shown). Four SM1-reactive meningococcal strains harboured DNA sequences that showed weak hybridization to the probe PS1 and all produced complete pilus structures. The most likely explanation of the reduced hybridization signal is that such strains retain only a single copy of the PS1 homologous sequence at the pilE locus and none at pilS loci. Presumably in most strains several of the pilS partial pilin copies retain the PS1homologous sequence and produce a more intense signal in dot-blots. A single meningococcal isolate, C786, that was non-piliated and failed to express SM1-reactive pilin, gave reproducibly low levels of hybridization to the probe PS1 (Fig. 5, position 2B). Similarly, non-piliated isogenic variants that do not produce SM1-reactive pilin that have been derived from $N$. meningitidis C311 and $N$. gonorrhoeae P9-2 show a reduced hybridization signal with the probe PS1 compared to their piliated or pilin-producing isogenic counterparts [Fig. 4; Fig. 5, positions 9A $\left(\mathrm{P9}-2 \mathrm{P}^{+}\right)$and $\left.9 \mathrm{~B}\left(\mathrm{P9}-2 \mathrm{P}^{-}\right)\right]$.

A single non-piliated isolate that did not react with SM1 and apparently did not possess genomic sequences encoding the SM1-reactive epitope was observed. It is possible that this isolate is a non-reverting $\mathbf{P}^{-}$variant derived from a class II pilus-producing strain. Of the ten class II pilus-producing isolates, five showed no detectable hybridization to the oligonucleotide PS1, and five showed weak hybridization with this probe (Table 1; Fig. 5).

Pili were seen on three strains of $N$. lactamica examined by electron microscopy, although none of these isolates expressed SM1-reactive pilin. DNA from these strains of $N$. lactamica exhibited only faint hybridization signals to the oligonucleotide probe PS1 (Fig. 5) or to the $0.42 \mathrm{~kb} \mathrm{BglI}-\mathrm{ClaI}$ fragment of recombinant pLV830 (data not shown). This may reflect the 
presence of sequences with only limited homology to the pilin gene. Three non-pathogenic isolates of the genus Neisseria ( $N$. pharyngis, $N$. flava and $N$. sicca) did not contain sequences homologous to the probe PSI, nor did they produce SM1-reactive pilin despite being demonstrably piliated.

\section{Occurrence of the SMI epitope and coding sequences in other bacterial genera}

Comparisons of the $\mathrm{N}$-terminal amino acid sequences of a number of the so called methylphenylalanine-type pilins have revealed homologies between pilins produced by Neisseria and those expressed by Bacteroides nodosus, Moraxella bovis, $M$. nonliquefaciens and Pseudomonas aeruginosa (Marrs et al., 1985; Olafson et al., 1985; Elleman et al., 1986; Pasloske et al., 1988). A number of clinical isolates of Gram-negative bacteria, including Aeromonas hydrophila, Bordetella pertussis, Pasteurella haemolytica, Moraxella liquefaciens, Pseudomonas stutzeri and Bacteroides fragilis were therefore tested for the expression of SM1-reactive pilin and the possession of the DNA sequences encoding this epitope. All isolates, with the exception of some strains of $B$. fragilis which exhibited very weak reactions, showed no homology to the oligonucleotide probe PS1 and failed to produce SM1-reactive pilin (data not shown). The amino acid sequence corresponding to the SM1-reactive epitope of pilin from Neisseria species is not evident in the analogous region of $B$. nodosus pilin. It is possible that there are partial homologies between DNA and amino acid sequences for pilins from $B$. fragilis (which have not yet been sequenced) and Neisseria species.

\section{DISCUSSION}

Physical confirmation of the minimum epitope recognized by monoclonal antibody SM1 to the sequence EYYLN, corresponding to amino acids 49-53 of mature neisserial pilin, is in accord with structural analysis of pilins from a number of different species. Mature gonococcal pilins contain three distinct domains, a highly conserved (C) region encompassing the first 53 amino acids, a semivariable (SV) region (approx. residues 54-114) in which amino acid substitutions occur, and a hypervariable (HV) region at the carboxy-terminus in which insertions and deletions of up to four amino acids occur (Hagblom et al., 1985; Nicolson et al., $1987 \mathrm{~b}$; Swanson et al., 1987). Sequence analysis of cloned class I meningococcal pilE (Potts \& Saunders, 1988) and pils (Perry et al., 1988) loci suggest that pilins produced by most strains of $N$. meningitidis also conform to this model, with complete homology between amino acids 1-55. In each case the sequence between residues 49 and 53 is preserved and the pili react with antibody SM1. In contrast, N-terminal homology between Neisseria pilin and the pilins produced by Moraxella, Pseudomonas and Bacteroides species does not extend beyond approximately residue 30 (Marrs et al., 1985; Saastry et al., 1983; Elleman et al., 1986; Pasloske et al., 1988), the EYYLN sequence is missing and the pili do not react with antibody SM1.

Previous studies (Virji \& Heckels, 1985) which suggested that mAb SM2 recognizes a conserved determinant in the carboxy-terminal portion of the pilin molecule have now been confirmed. Although this region contains the hypervariable determinants, conserved sequences occur around the two cysteine residues which form the disulphide loop (Hagblom et al., 1985). In contrast to the SM1 epitope, the studies described here do not define a simple linear peptide for the SM2 epitope. $\mathrm{mAb} \mathrm{SM} 2$ reacts with a number of peptides from around the Cys 1 at position 120 , suggesting that this extended region may contribute to a conformational epitope recognized by the antibody in native pilin. This would be in accord with previous observations that mAb SM2 reacts much less strongly on Western blots of SDS-denatured pilin than does $\mathrm{mAb}$ SM1 (Virji et al., 1983). As would be expected from the reactivity of SM2, this region is also highly conserved not only in gonococci but also in the class I pilin gene of meningococcal strain C311 (Potts \& Saunders, 1988) but is absent from the Moraxella, Bacteroides and Pseudomonas pilins.

Pilin genes encoding class II meningococcal pilin have not yet been cloned and no sequence information is available. It is likely from hybridization and sequence data that the structural gene for class II pilin will possess only limited nucleotide sequence homology to the class I pilE gene (Perry et al., 1988). The current studies reveal that differences between the two classes of 
meningococcal pilin are likely to be extensive and not simply the result of the deletion of a limited number of amino acids in a single domain. Despite the quite different locations of the determinants recognized by the two mAbs, class II pili do not react with either antibody. These pili also fail to react on Western blots with polyclonal sera raised against gonococcal pili, although they do react with the same sera in immune precipitation under less denaturing conditions (Diaz et al., 1984). This suggests that the class II pili differ at the level of primary amino acid sequence but nevertheless contain conformational determinants similar to those found on class I and gonococcal pili. If this is the case it would imply conservation at the functional level and indicate a common role for two pilus classes.

This study confirms that the majority of strains of $N$. meningitidis, regardless of serotype, elaborate class I pili which are characterized by the possession of an amino-terminal $\mathrm{C}$ region containing the relatively weakly immunogenic linear EYYLN epitope recognized by mAb SM1. All SM1-reactive isolates of $N$. meningitidis, and all gonococcal isolates tested, not surprisingly harboured genomic sequences that hybridized to the oligonucleotide probe PS1. Some meningococcal strains were non-piliated, but produced SM1-reactive pilin. Pilus phase variation in $N$. gonorrhoeae can result from recombination between pilS loci and the pilE locus, producing defective pilin gene products. Such defective pilins are immunologically reactive, but are not assembled into pili, giving rise to a non-piliated phenotype (Bergstrom et al., 1986; Haas et al., 1987; Swanson et al., 1986). Such non-piliated gonococcal variants can readily revert to the piliated phenotype. It is evident that pilin-producing $\mathbf{P}^{-}$variants are also generated in $N$. meningitidis (Stephens et al., 1985; this study).

DNA dot-blot analysis of piliated and non-piliated SM1-reactive meningococci revealed that the majority of isolates showed strong hybridization signals with the probe PS1. However, four strains that produced SM1-reactive pilus structures exhibited weak hybridization with this probe, suggesting that there are relatively few copies of PS1-homologous sequences in their genomes. This would be consistent with a variety of Southern hybridization patterns that are observed when different strains of $N$. meningitidis are hybridized with the gonococcal pilE gene as probe (Perry et al., 1987a). N. gonorrhoeae can undergo irreversible $\mathbf{P}^{+}$to $\mathrm{P}^{-}$pilus phase variation as the result of genomic DNA rearrangements that lead to deletion of the $5^{\prime}$ end of the pilin structural gene (Meyer et al., 1982; Nicolson et al., 1987 a; Segal et al., 1985). Similarly the class I pilus-producing meningococcal strain C311 exhibits phase variation, accompanied in a proportion of cases by deletion of pilE-related sequences (Perry et al., 1987a). This study indicates that such deletions of pilin gene sequence in non-piliated variants of $N$. gonorrhoeae P9-2 and $N$. meningitidis $\mathrm{C} 311$ are correlated with a reduced hybridization signal in DNA dotblots with the oligonucleotide PS1 when compared to signals obtained with isogenic piliated variants of these strains. Nevertheless, none of the non-reverting $\mathrm{P}^{-}$derivatives of $N$. meningitidis that we have isolated following growth in vitro have exhibited deletion of all PS1homologous sequences.

Of the 40 meningococcal isolates examined in this study, fewer produced class II pili than produced class I pili. Five of the 10 class II pilus-producing strains showed no detectable homology to the PS1 probe whereas the remainder reacted weakly. All meningococci and gonococci tested harboured sequences homologous to the 3 '-proximal SV and HV regions of the class I meningococcal pilE gene. This confirms that all class II piliated isolates retain part of the class I pilus sequence which is silent because it lacks $5^{\prime}$ sequences containing the pilE promoter. These observations are consistent with our previous studies of the class II pilus-producing strain C114 in which the only sequences homologous to the gonococcal pilE gene are two tandem truncated pilS copies comprising pilin codons 79-144 (copy 1) and 64-150 (copy 2) (Perry et al., 1988). A similar arrangement has subsequently been observed in the pilS locus of FAM18, an unrelated strain of $N$. meningitidis (Aho \& Cannon, 1988). The class II pilus-producing meningococci that showed faint hybridization signals with the PS1 probe probably harbour silent pilin gene copies that are not expressed but still retain the coding sequence for the SM1reactive epitope. Presumably the class I pilS sequences present extend further towards the Nterminal coding portion of the pilin gene than those sequences in strains C114 and FAM18. Interestingly, three of the four strains of $N$. lactamica also showed faint hybridization signals 
with the probe PS1 but elaborated pili that did not react with mAb SM1. This is reminiscent of the situation observed in this second type of class II pilus-producing strains of $N$. meningitidis. Experience with non-reverting $\mathrm{P}^{-}$derivatives of gonococci in which pilin and $\mathrm{N}$-terminal coding sequences are deleted (Swanson et al., 1986; Segal et al., 1985) suggests that class II meningococcal strains with either type of residual class I pil sequences are unlikely to be able to regain the ability to produce class I pili. However, it is conceivable, by analogy with gonococci (Seifert et al., 1988), that defects in class I pilin production might be repaired following the acquisition of a complete complement of pilE sequences by transformation. Nevertheless, these strains have probably elaborated class I pili at some stage in their evolutionary history.

Aho et al. (1987) showed that some strains of $N$. lactamica contained sequences homologous to an intact gonococcal pilE gene probe. Three of the piliated strains of $N$. lactamica examined in our study exhibited weak hybridization reactions with the PS1 probe. The presence of class I pil DNA sequences in $N$. lactamica, which is commonly regarded as a commensal, is consistent with a number of reports that members of this species can occasionally cause infections at different sites in humans (Johnson, 1983; Brown et al., 1987). In addition, $N$. lactamica shares further characteristics with $N$. meningitidis and $N$. gonorrhoeae, including expression of the H8 antigen and possession of DNA sequences related to the gonococcal opa (heat-modifiable outermembrane protein PII) gene (Cannon et al., 1984; Black \& Cannon, 1985; Aho et al., 1987; Stern \& Meyer, 1987). These observations support the idea that a divergent evolutionary development has separated these three species from other members of the genus. Class I neisserial pilin sequences were not detected in the genomes of a number of non-pathogenic members of the genus Neisseria that were tested in this study. This supports the contention that sequences homologous to the gonococcal pilin gene are essentially diagnostic for the pathogenic members of the genus (Aho et al., 1987). However, our study shows that for a proportion of meningococci such sequence conservation is limited to residual pilS sequences that lack the $5^{\prime}$ end of the gonococcal pilE gene.

This work was supported by project grants from the Medical Research Council and the Meningitis Trust. Part of the work was supported by a Leave Fellowship to J.R.S. from the Wellcome Trust. W.J.P. is grateful for a postgraduate scholarship from the Medical Research Council. We thank T. Knapp, Royal Liverpool School of Tropical Medicine, for synthesis of oligonucleotides.

\section{REFERENCES}

Achtman, M., Crowe, B. A., Olyhoek, A., StrittMATTER, W. \& MORELli, G. (1988). Recent results on epidemic meningococcal meningitis. Journal of Medical Microbiology 26, 161-187.

Aно, E. L. \& CANNON, J. G. (1988). Characterization of a silent pilin gene locus from Neisseria meningitidis strain FAM18. Microbial Pathogenesis 5, 391-398.

Aho, E. L., Murphy, G. L. \& Cannon, J. G. (1987). Distribution of specific DNA sequences among pathogenic and commensal Neisseria species. Infection and Immunity 55, 1009-1013.

Bergstrom, S., Robbins, K., KoOMey, M. K. \& Swanson, J. (1986). Piliation control mechanisms in Neisseria gonorrhoeae. Proceedings of the National Academy of Sciences of the United States of America 83, 3890-3894.

Black, W. J. \& Cannon, J. G. (1985). Cloning of the gene for the common pathogenic Neisseria H.8 antigen from Neisseria gonorrhoeae. Infection and Immunity 47, 322-325.

Brown, N. M., Ragge, N. K. \& Speller, D. C. E. (1987). Septicaemia due to Neisseria lactamica initial confusion with Neisseria meningitidis. Journal of Infection 15, 243-245.

Cannon, J. G., Black, W. J., Nachamkin, I. \&
STEWART, P. (1984). Monoclonal antibody that recognises an outer membrane antigen common to the pathogenic Neisseria species but not to most nonpathogenic Neisseria species. Infection and Immunity 43, 994-999.

DiAz, J.-L., VIRJI, M. \& HeCKels, J. E. (1984). Structural and antigenic differences between two types of meningococcal pili. FEMS Microbiology Letters 21, 181-184.

Elleman, T. C., Hoyne, P. A., Stewart, D. J., McKern, N. M. \& Peterson, J. E. (1986). Nucleotide sequence of the gene encoding the two-subunit pilin of Bacteroides nodosus. Journal of Bacteriology 167, 243-250.

Feinberg, A. P. \& Vogenstein, B. (1983). A technique for radiolabelling DNA restriction endonuclease fragments to high specific activity. Analytical Biochemistry 132, 6-13.

Geysen, H. M., Rodda, S. J., Mason, T. J., Tribiick, G. \& Schoofs, P. G. (1987). Strategies for epitope analysis using peptide synthesis. Journal of Immunological Methods 103, 259-274.

Gill, P., Jefrreys, A. J. \& Werret, D. J. (1985). Forensic application of DNA 'fingerprints'. Nature, London 318, 577-579. 
Greenblatt, J. J., Floyd, K., Philupps, M. E. \& FrasCH, C. E. (1988). Morphological differences in Neisseria meningitidis pili. Infection and Immunity 56, 2356-2362.

HAÁ, R. \& MEYER, T. F. (1986). The repertoire of silent pilus genes in Neisseria gonorrhoeae: evidence for gene conversion. Cell 44, 107-115.

HAas, R., Schwartz, H. \& MEYER, T. F. (1987). Release of soluble pilin antigen coupled with gene conversion in Neisseria gonorrhoeae. Proceedings of the National Academy of Sciences of the United States of America 84, 9079-9083.

Hagblom, P., Segal, E., Billyard, E. \& So, M. (1985). Intragenic recombination leads to pilus antigenic variation in Neisseria gonorrhoeae. Nature, London 315, 156-158.

HANAHAN, D. (1983). Studies on transformation of Escherichia coli with plasmids. Journal of Molecular Biology 166, 557-580.

HECKELS, J. E. (1989). Structure and function of pili of pathogenic Neisseria species. Clinical Microbiology Reviews 2, S66-S73.

HECKELS, J. E. \& VIRJI, M. (1986). Antigenic variation of gonococcal surface proteins: effect on virulence. In Protein-Carbohydrate Interactions in Biological Systems, pp. 89-94. Edited by D. L. Lark. London: Academic Press.

Hermodsen, M. A., Chen, C. S. \& Buchanan, T. M. (1978). Neisseria pili proteins: amino-terminal sequences and identification of an unusual amino acid. Biochemistry 17, 442-445.

HITCHCOCK, P. J. (1989). Unified nomenclature for pathogenic Neisseria species. Clinical Microbiology Reviews 2, 564-565.

JoHnson, A. P. (1983). The pathogenic potential of commensal species of Neisseria. Journal of Clinical Pathology 36, 213-223.

Kellog, D. S., Peacock, W. L., Deacon, W. E., Brown, L. \& PIRKLE, C. I. (1963). Neisseria gonorrhoeae. I. Virulence genetically linked to clonal variation. Journal of Bacteriology 85, 1274-1279.

Kristiansen, B. E., Sorensen, B., Simonsen, T., SpanNe, O., Lund, V. \& BJoRvatn, B. (1984). Isolates of Neisseria meningitidis from different sites in the same patients: phenotypic and genomic studies with special reference to adherence, piliation and DNA restriction. Journal of Infectious Diseases 150, 389-396.

Lambden, P. R., Heckels, J. E., McBride, H. \& WATT, P. J. (1981). The identification and isolation of novel pilus types produced by variants of Neisseria gonorrhoeae following selection in vivo. FEMS Microbiology Letters 10, 339-341.

Marrs, C. F., Schoolnik, G., KoOmey, J. M., Hardy, J., Rothbard, J. \& Falkow, S. (1985). Cloning and sequencing of a Moraxella bovis pilin gene. Journal of Bacteriology 163, 132-139.

Meyer, T. F., Mlawer, N. \& So, M. (1982). Pilus expression in $N$. gonorrhoeae involves chromosomal rearrangement. Cell 30, 45-52.

Nicolson, I. J., Perry, A. C. F., Heckels, J. E. \& SAUNDERS, J. R. (1987a). Genetic analysis of variant pilin genes from Neisseria gonorrhoeae $\mathrm{P} 9$ cloned in Escherichia coli: physical and immunological properties of encoded pilins. Journal of General Microbiology 133, 553-561.
Nicolson, I. J., Perry, A. C. F., Virji, M., Heckels, J. E. \& SAUNDERS, J. R. $(1987 b)$. Localization of antibody-binding sites by sequence analysis of cloned pilin genes from Neisseria gonorrhoeae. Journal of General Microbiology 133, 825-833.

Olafson, R. W., McCarthy, P. J., Bhatti, A. R., Dooley, J. S. G., Heckels, J. E. \& Trust, T. J. (1985). Structural and antigenic analysis of meningococcal piliation. Infection and Immunity 48, 336342.

O'Reilly, M., de Azavedo, J. C. S., Kennedy, S. \& FOSTER, T. J. (1986). Inactivation of the alphahaemolysin gene of Staphylococcus aureus $8325-4$ by site-directed mutagenesis and studies on the expression of its haemolysins. Microbial Pathogenesis 1, $125-138$.

Pasloske, B. L., Joffe, M., Sun, Q., Volpel, K., Paranchych, W., EfTekhar, F. \& Speert, D. P. (1988). Serial isolates of Pseudomonas aeruginosa from a cystic fibrosis patient have identical pilin sequences. Infection and Immunity 56, 665-672.

Perry, A. C. F., Hart, C. A., Nicolson, I. J., HeCKels, J. E. \& SAunders, J. R. (1987a). Interstrain homology of pilin gene sequences in Neisseria meningitidis isolates that possess markedly different antigenic pilus types. Journal of General Microbiology 133, 1409-1418.

Perry, A. C. F., Nicolson, I. J. \& Saunders, J. R. $(1987 \mathrm{~b})$. Structural analysis of the pilE region of Neisseria gonorrhoeae P9. Gene 60, 85-92.

Perry, A. C. F., Nicolson, I. J. \& Saunders, J. R. (1988). Neisseria meningitidis strain $\mathrm{C} 114$ contains silent, truncated pilin genes that are homologous to Neisseria gonorrhoeae pil sequences. Journal of Bacteriology 170, 1691-1697.

PotTs, W. J. \& Saunders, J. R. (1988). Nucleotide sequence of the structural gene for class I pilin from Neisseria meningitidis: homologies with the pilE locus of Neisseria gonorrhoeae. Molecular Microbiology 2, 647-653.

Saastry, P. A., Pearlstone, L. B., Smillie, L. B. \& Paranchych, W. (1983). Amino acid sequence of pilin isolated from Pseudomonas aeruginosa PAK. FEBS Letters 151, 253-256.

Schoolnik, G. K., Fernandez, R., TAI, J. Y., RothbaRd, J. \& GoTSCHLICH, E. C. (1984). Gonococcal pili: primary structure and receptor binding domain. Journal of Experimental Medicine 159, 1351-1370.

Segal, E., Billyard, E., So, M., Storzbach, S. \& MEYER, T. F. (1985). Role of chromosomal rearrangement in $N$. gonorrhoeae pilus phase variation. Cell 40, 293-300.

Segal, E., Hagblom, P., Seifert, H. S. \& So, M. (1986). Antigenic variation of gonococcal pilus involves assembly of separated silent gene segments. Proceedings of the National Academy of Sciences of the United States of America 83, 2177-2181.

Seifert, H. S., Aujoka, R. S., Marchal, C., SparLING, P. F. \& So, M. (1988). DNA transformation leads to pilin antigenic variation in Neisseria gonorrhoeae. Nature, London 336, 392-395.

StePhens, D. S. \& MCGeE, Z. A. (1981). Attachment of Neisseria meningitidis to human mucosal surfaces: influence of pili and type of receptor cell. Journal of Infectious Disease 143, 525-532. 
Stephens, D. S., Whitney, A. M., Rothbard, J. \& SchoOLNIK, G. K. (1985). Pili of Neisseria meningitidis. Analysis of structure and investigation of structural and antigenic relationships to gonococcal pili. Journal of Experimental Medicine 161, 1539-1553.

Stern, A. \& Meyer, T. F. (1987). Common mechanism controlling phase and antigenic variation in pathogenic neisseriae. Molecular Microbiology 1, 5-12.

Sullivan, K. M. \& Saunders, J. R. (1989). Nucleotide sequence and genetic organization of the NgoPII restriction-modification system of Neisseria gonorrhoeae. Molecular and General Genetics 216, 380-387.

SWANSON, J. (1973). Studies on gonococcal infection. IV. Pili: their role in attachment of gonococci to tissue culture cells. Journal of Experimental Medicine 137, 571-589.

Swanson, J., Kraus, S. J. \& Gotschlich, E. C. (1971). Studies on gonococcus infection. I. Pili and zones of adhesion: their relation to gonococcal growth patterns. Journal of Experimental Medicine 134, 886-906.

Swanson, J., Bergstrom, S., Robbins, K., Barrera, O., Corwin, D. \& Koomey, J. M. (1986). Gene conversion involving the pilin structural gene correlates with pilus ${ }^{+}$to pilus ${ }^{-}$changes in Neisseria gonorrhoeae. Cell 47, 267-276.

Swanson, J., Robbins, K., Barrera, O., Corwin, D., Boslego, J., Ciak, J., Blake, M. \& KoOmey, M. J. (1987). Gonococcal pilin variants in experimental gonorrhoea. Journal of Experimental Medicine 165, 1344-1357.

Tinsley, C. R. \& HeCKels, J. E. (1986). Variation in the expression of pili and outer membrane protein by Neisseria meningitidis during the course of meningococcal infection. Journal of General Microbiology 132, 106-113.
Trust, T. J., Gillespie, R. M., Bhatti, A. R. \& WhITE, L. A. (1983). Differences in the adhesive properties of Neisseria meningitidis from human buccal epithelial cells and erythrocytes. Infection and Immunity 41, 106-113.

VIRJI, M. \& HeCKels, J. E. (1983). Antigenic crossreactivity of Neisseria pili: investigations with typeand species-specific monoclonal antibodies. Journal of General Microbiology 129, 2761-2768.

VIRJI, M. \& Heckels, J. E. (1985). Role of anti-pilus antibodies in host defense against gonococcal infection studied with monoclonal antibodies. Infection and Immunity 49, 621-628.

VIRJI, M. \& HeCKELS, J. E. (1989). Location of a blocking epitope on outer membrane protein III of Neisseria gonorrhoeae by synthetic peptide analysis. Journal of General Microbiology 135, 1895-1899.

VirJi, M., Everson, J. S. \& Lambden, P. R. (1982). Effect of anti-pilus antisera on virulence of variants of Neisseria gonorrhoeae for cultured epithelial cells. Journal of General Microbiology 128, 1095-1100.

VirJi, M., Heckels, J. E. \& WaTt, P. J. (1983). Monoclonal antibodies to goonococcal pili: studies on antigenic determinants on pili from variants of strain P9. Journal of General Microbiology 129, 1965-1973.

WARD, M. E., WATt, P. J. \& Robertson, J. N. (1974). The human fallopian tube: a model for gonococcal infection. Journal of Infectious Diseases 129, 650-659.

ZaK, K., Diaz, J-L., Jackson, D. \& Heckels, J. E. (1984). Antigenic variation during infection with Neisseria gonorrhoeae: detection of antibodies to surface proteins in sera of patients with gonorrhoea. Journal of Infectious Diseases 149, 166-173. 